\title{
ANALISIS FAKTOR YANG MEMPENGARUHI INVESTASI ASING LANGSUNG DI INDONESIA PADA TAHUN 1989 - 2019
}

\author{
Elis Laili Khoirun Nisa, ${ }^{\text {, }}$ Whinarko Juliprijanto ${ }^{2}$ \\ ${ }^{1,2}$ Fakultas Ekonomi, Universitas Tidar, Indonesia \\ Jl. Kapten Suparman No.39 Magelang, Indonesia \\ E-mail: ${ }^{1)}$ elislaili7@gmail.com, ${ }^{2}$ juliprijanto@yahoo.com
}

\begin{abstract}
Abstrak
Penelitian ini memiliki tujuan mengetahui hubungan antara PDB, Tenaga kerja, Ekspor dan Kurs terhadap Investasi Asing Langsung atau Foreign Direct Investment di Indonesia dari tahun 1986 sampai 2019. Menggunakan data time series, teknik analisis data menggunakan Error Correction Model (ECM), kemudian dilanjutkan olah data dengan Eviews 10. Hasil analisis menunjukkan perhitungan jangka panjang variabel PDB tidak signifikan akan tetapi berpengaruh positif, Ekspor berpengaruh signifikan, sedangkan tenaga kerja dan kurs berpengaruh negatif dan tidak signifikan. Selanjutnya hasil analisis jangka pendek, variabel PDB dan Kurs tidak signifikan serta bernilai negatif, sedangkan untuk variabel Ekspor dan Tenaga kerja tidak signifikan dan bernilai positif.
\end{abstract}

Kata Kunci: Produk Domestik Bruto, Tenaga Kerja, Ekspor, Investasi Asing Langsung, Kurs

\begin{abstract}
This research aims to find out the relationship between GDP, Labor, Exports and Exchange Rates to foreign direct investment in Indonesia from 1986 to 2019. Using time series data, data analysis techniques use the Error Correction Model (ECM) model, which is then followed by Eviews 10. The results of the analysis showed that the long-term calculation of GDP variables was not significant but had a positive effect, exports had a significant effect, while labor and exchange rates had a negative and insignificant effect. Furthermore, the results of short-term analysis, GDP and Exchange Rate variables are insignificant and negative value, while for Export and Labor variables are insignificant and positive value.
\end{abstract}

Keywords: Gross Domestic Product, Labor, Exports Foreign Direct Investment, Exchange Rate

\section{PENDAHULUAN}

Indonesia merupakan negara yang bersifat terbuka pada sistem ekonominya. Dalam rangka ikut serta dan menjaga kestabilan pertumbuhan ekonomi, kebijakan ekonomi pemerintah menerima campur tangan pihak dalam negeri maupun luar negeri secara terbuka. Sebagai pemicu pembangunan negara, kebutuhan terkait investasi adalah sangat penting. Pentingnya investasi adalah agar mencapai pembangunan ekonomi yang diinginkan ketika terjadi keterbatasan dana yang dimiliki suatu negara. Salah satu bentuk investasi yaitu investasi asing langsung atau FDI (Foreign Direct Investment) yang berdampak signifikan dibandingkan investasi berbentuk portofolio. Pendirian pabrik merupakan transfer modal, selain itu merupakan pusat pertumbuhan, serta membuka lapangan kerja, selain itu FDI bermanfaat untuk transfer manajemen, teknologi dan ilmu pengetahuan, serta meningkatkan pendapatan pajak negara. Jadi bagi peneliti, sangat penting mengetahui kondisi FDI di 
Indonesia, jadi para pemangku kebijakan dapat mengambil kebijakan yang efektif terkait aliran FDI ke Indonesia.

Beberapa hal yang dapat berpengaruh terhadap FDI antara lain meliputi suku bunga kredit, produk domestik bruto, inflasi, serta variabel ada tidaknya krisis. Metode analisis datanya adalah regresi linier dengan sumber datanya adalah rentet waktu atau time series pada tahun 1986 hingga 2019. Selama pembangunan perekonomian, Indonesia menghadapi beberapa masalah, salah satunya terkait permasalahan dana. Dalam pelaksanaan pembangunan perekonomian, ketersediaan dana belum mampu mencukupi untuk melakukan pembangunan ekonomi di Indonesia. Nilai tabungan domestik belum cukup dalam pemenuhan investasi yang diperlukan. Selain memanfaatkan sumber dana dari dalam negeri, pemerintah juga berupaya menarik masuk minat investor luar negeri. Harrod Dommar mengatakan bahwa "adanya investasi merupakan syarat wajib untuk melakukan pembangunan ekonomi disuatu negara". Berdasarkan pendapat tersebut pemerintah perlu berusaha agar investasi asing masuk ke Indonesia.

Jenis Investasi asing dibagi menjadi 2 yaitu tidak langsung (portofolio) dan langsung (foreign direct investment). FDI berkaitan dengan pemberian modal dari pihak asing di beberapa sektor ekonomi di Indonesia. Investasi langsung dari pihak luar negeri seperti ini bermanfaat untuk sumber pembiayaan guna menutup kekurangan pembiayaan pembangunan perekonomian. Portofolio yaitu penanaman modal berjangka pendek, berbentuk aset finansial seperti saham dan obligasi (Lembong, 2013). FDI merupakan investasi oleh perusahaan di suatu negara yang ditujukan ke perusahaan di negara lain yang bertujuan agar dapat mengontrol operasional perusahaan yang diberi investasi, agar terjalin koneksi antara perusahaan induk dengan perusahaan afiliasinya. Sehingga syarat agar sebuah investasi dianggap FDI adalah keharusan dapat mengontrol perusahaan afiliasinya. Syarat lainya yaitu kepemilikan saham atas suatu perusahaan minimal 10\% dan jika kurang dari angka tersebut jenis investasinya adalah portofolio (Zsaszya, 2019).

Untuk negara yang dianggap masih negara terbelakang, kebutuhan akan investasi sangatlah penting. Mayoritas negara yang sekarang dianggap sebagai negara maju awalnya dimulai dengan adanya investasi di negara tersebut. Karakteristik dari negara terbelakang adalah adanya kekurangan modal untuk pembangunan ekonomi, sehingga kebutuhan akan modal asing sangat diperlukan yaitu dengan penerimaan investasi asing (Jhingan, 1988). Dengan adanya investasi asing akan tercipta pembangunan ekonomi dan industrialisasi, yang akan berdampak pada luasnya lapangan kerja serta meningkatnya sumber daya manusia dikarenakan kebutuhan dari industri. Sehingga adanya investasi asing selain akan meningkatkan pembangunan akan tetapi juga menciptakan masyarakat yang lebih modern dikarenakan kebutuhan industri yang semakin kompleks.

Indonesia adalah Negara berkembang yang belum mampu mencapai pembangunan yang ideal sesuai negara maju lainya. Penyebabnya adalah tabungan domestik yang belum mampu mencukupi kebutuhan akan investasi sehingga Indonesia masih memerlukan investasi asing untuk mengejar ketertinggalan tersebut. Menurut Sumarni \& Rahmawati, 2007) adanya kesenjangan antar kebutuhan investasi dan tabungan domestik, mengharuskan pencarian alternatif lain. Sehingga, selain perlu mencari sumber modal dalam negeri, pemerintah diharuskan mencari modal dari asing, baik itu berupa investasi asing, hutang luar negeri, maupun hibah. Akan tetapi jika pemerintah mencari alternatif untuk kebutuhan pembangunan dengan utang luar negeri maka akan berdampak pada terbebaninya negara 
dengan kewajiban pembayaran hutang serta bunganya yang biasanya nilainya cukup tinggi. Sehingga alternatif paling rasional dan efektif sebagai pemenuhan kebutuhan akan pembangunan di suatu negara adalah dengan menarik investasi asing baik itu FDI maupun portofolio. Kedua jenis investasi asing tersebut memiliki karakteristik yang berbeda-beda. FDI adalah jenis investasi asing yang dapat berupa pendirian pabrik dan sejenisnya. Investor asing memiliki hak untuk terlibat ke dalam manajerial perusahaan yang diberi modal. Sedangkan portofolio adalah bentuk investasi yang berupa aset finansial seperti obligasi dan saham. Dalam jenis investasi portofolio investor tidak mempunyai hak manajerial perusahaan.

Menurut Sarwedi, 2002), investasi asing secara spesifik dapat juga berupa modal, keahlian manajemen, serta teknologi, dimana pemanfaatannya disesuaikan berdasarkan kebutuhan pembangunan. Investasi FDI merupakan sumber modal asing yang paling potensial dikarenakan memiliki tujuan jangka panjang sehingga dapat lebih berkontribusi terhadap pembangunan di suatu negara dibandingkan dengan jenis investasi portofolio yang hanya bergerak dalam investasi jangka pendek. Menurut beberapa ekonom FDI lebih menguntungkan signifikan dari pada portofolio. Hal tersebut bias terjadi dikarenakan efek FDI yang berupa modal, teknologi dan ilmu pengetahuan akan sangat berguna bagi suatu negara. Sedangkan investasi portofolio tidak berpengaruh signifikan dalam hal pembangunan ekonomi di suatu negara. Perkembangan FDI Indonesia dari tahun 1989 2019 dipaparkan dalam tabel berikut:

Tabel 1 Perkembangan FDI di Indonesia Pada Tahun 1989 - 2019

\begin{tabular}{llllll}
\hline Tahun & FDI & GDP & Ekspor & TK & Kurs \\
\hline 1989 & 682000000 & 94451427898 & 24640067883 & 109728517 & 1770 \\
1990 & 1093000000 & 106140727357 & 28982531190 & 113087806 & 1843 \\
1991 & 1482000000 & 116621996217 & 33063806609 & 115144670 & 1950 \\
1992 & 1777000000 & 128026966580 & 38801726176 & 117704445 & 2030 \\
1993 & 2004000000 & 158006700302 & 42274397859 & 120301486 & 2087 \\
1994 & 2109000000 & 176892143932 & 46896633114 & 124827173 & 2161 \\
1995 & 4346000000 & 202132028723 & 53185312942 & & 2249 \\
1996 & 6194000000 & 227369679375 & 58717201042 & 131375264 & 2342 \\
1997 & 4677000000 & 215748998610 & 60106038404 & 134548441 & 2909 \\
1998 & -240800000 & 95445547873 & 50555726235 & 138003713 & 10014 \\
1999 & -1865620963 & 140001351215 & 49720260590 & 141096417 & 7855 \\
2000 & -4550355286 & 165021012078 & 67621169166 & 141170805 & 8422 \\
2001 & -2977391857 & 160446947785 & 62625875834 & 144033873 & 10261 \\
2002 & 145085548.722 & 195660611165 & 63956798805 & 148729934 & 9311 \\
2003 & -596923827.7862 & 234772463824 & 71553141045 & 151406298 & 8577 \\
2004 & 1896082770 & 256836875295 & 82744351781 & 153923648 & 8939 \\
& & & & 158491396 &
\end{tabular}




\begin{tabular}{llllll}
\hline 2005 & 8336257208 & 285868618224 & 97387627235 & 160811498 & 9705 \\
2006 & 4914201435 & 364570514305 & 113143424880 & 164118323 & 9159 \\
2007 & 6928480000 & 432216737775 & 127226102177 & 166641050 & 9141 \\
2008 & 9318453650 & 510228634992 & 152090401422 & 169328208 & 9699 \\
2009 & 4877369178 & 539580085612 & 130357798591 & 172070339 & 10390 \\
2010 & 15292009411 & 755094160363 & 183480563627 & 173851717 & 9090 \\
2011 & 20564938227 & 892969107923 & 235095130018 & 173851717 & 8770 \\
2012 & 21200778608 & 917869910106 & 225744402474 & 179967361 & 9387 \\
2013 & 23281742362 & 912524136718 & 218308408828 & 182992204 & 10461 \\
2014 & 25120732060 & 890814755233 & 210820082761 & 186100917 & 11865 \\
2015 & 19779127977 & 860854235065 & 182158299305 & 189096722 & 13389 \\
2016 & 4541713739 & 931877364178 & 177886012772 & 192079416 & 13308 \\
2017 & 20510310832 & 1015618742566 & 204924485588 & 198126553 & 13381 \\
2018 & 18909826044 & 1042240309413 & 218580936571 & 201185014 & 14237 \\
2019 & 24993551748 & 1119190780753 & 206015217322 & & 14148 \\
\hline
\end{tabular}

Sumber : Word Bank

Berdasarkan tabel 1 yang berasal dari data word bank dapat dilihat jika FDI di Indonesia pada 1986 - 2019 berada dalam fluktuasi dari tahun ke tahun selama 33 tahun ini. Investasi asing langsung (FDI) mencapai angka tertinggi pada 2019 yaitu sebesar 24993551748 US \$, dan berada di titik terendah pada tahun 2003 sebesar 596923827.786241.

Pemerintah Indonesia di tahun 2007 memperbarui peraturan perundang-undangan terkait penanaman modal dengan menerbitkan UU Nomor 25 tahun 2007. Tujuan pembaruan undang-undang tersebut adalah untuk meningkatkan investasi dalam negeri maupun investasi asing. Pembaruan undang-undang tersebut terbukti meningkatkan jumlah investor asing di Indonesia. Terbukti dari data realisasi FDI dari tahun 2007 sampai 2013 yang terus mengalami peningkatan, meskipun di tahun 2009 angka FDI menurun, yang bersamaan dengan angka penurunan proyek pembangunan.

Masuknya FDI di Indonesia bukan hanya meningkatkan output riil, akan tetapi FDI secara langsung juga memberi kemampuan teknologi dan manajerial yang tentunya dibutuhkan di Indonesia sebagai negara berkembang. Pemerintah perlu mengetahui faktorfaktor yang mempengaruhi FDI di Indonesia, sehingga dapat mengambil kebijakan yang tepat agar dapat menarik investor asing. Dengan begitu pembangunan di Indonesia akan berkembang dengan baik.

\section{LANDASAN TEORI}

\subsection{Foreign Direct Investment (FDI)}

Dalam konsepnya investasi asing bertujuan merubah sumber potensial menjadi sebuah sumber kekuatan ekonomi yang bertujuan untuk meningkatkan kemakmuran dan 
pembangunan yang lebih baik bagi warga negara. Secara teoretis investasi dari luar negeri dibagi menjadi 2 jenis yaitu investasi asing langsung atau Foreign Direct Investment serta investasi asing tidak langsung atau portofolio. Berbeda dengan portofolio yang berfokus pada investasi jangka pendek, FDI lebih berfokus pada pembelian saham di bursa efek dengan tujuan memperoleh imbalan keuntungan. Perbedaan paling konseptual antara FDI dengan portofolio adalah FDI membutuhkan kendali manajemen dari investor sedangkan untuk portofolio tidak membutuhkan kontrol manajemen dari investor (Lembong, 2013). Menurut studi Gupta terkait dengan investasi asing ataupun bantuan luar negeri, keduanya sama-sama memiliki kontribusi yang positif terhadap pembangunan di suatu negara (Hatemi-J \& Irandoust, 2005). Hasil penelitian oleh Gulati yang dilakukan menggunakan data time series menunjukkan bahwa bantuan luar negeri dan investasi asing, keduanya saling berpengaruh positif terhadap pemenuhan modal guna keperluan pembangunan disuatu negara (Hatemi-J \& Irandoust, 2005)).

\subsection{Gross Domestic Product (GDP)}

GDP atau PDB adalah bagian penting terkait sumber pendapatan suatu negara. Menurut penelitian Sukirno (2011), PDB adalah nilai barang/jasa berdasarkan faktor-faktor produksi di suatu negara yang berkesinambungan dengan negara lainya. Sedangkan menurut Latumaerissa (2015) PDB merupakan nilai barang jasa pada periode tertentu atau pada tahun tertentu, diproduksi perusahaan di negara tersebut maupun penduduk lainya selama perusahaan masih berdiri di negara tersebut (Lembong, 2013).

Penelitian yang dilakukan Eliza (2013), menunjukkan bahwa variabel suku bunga dan PDB mempengaruhi FDI di Indonesia baik secara jangka panjang ataupun jangka pendek . Akan tetapi variabel kurs serta variabel inflasi tidak berpengaruh kepada investasi asing di Indonesia baik secara jangka panjang maupun secara jangka pendek. Terkait dengan investasi jangka panjang hanya variabel PDB yang berpengaruh pada investasi asing di Indonesia sedangkan variabel-variabel lainya tidak berpengaruh.

\subsection{Ekspor}

Pengertian dari ekspor yaitu pembelian barang produksi dalam negeri yang dilakukan oleh negara lain (Benny, 2013). Ekspor mencakup semua transaksi yang terjadi antara penduduk negara dan seluruh dunia yang mencakup perubahan kepemilikan dari warga ke yang bukan warga dari barang dagangan umum, ekspor bersih barang di bawah pedagang emas non-moneter, dan jasa .

Berdasarkan penelitian yang dilakukan oleh Febriana \& Muqorobbin (2002), bahwa pertumbuhan ekonomi berpengaruh signifikan terhadap FDI baik dalam jangka panjang ataupun jangka pendek. Pada jangka pendek kurs berpengaruh positif serta signifikan terhadap FDI dan pada jangka panjang tidak berpengaruh signifikan terhadap FDI. Sedangkan pada jangka pendek ekspor berpengaruh signifikan dan positif terhadap variabel FDI serta pada jangka panjang bernilai negatif dan tidak berpengaruh signifikan terhadap FDI.

\subsection{Tenaga Kerja}

Definisi dari tenaga kerja yaitu individu yang memproduksi barang serta jasa, untuk memenuhi keperluan pribadi ataupun keperluan perusahaan (KEMENPERIN, 2003). 
Selanjutnya pengertian menurut KBBI, definisi dari tenaga kerja yaitu orang yang melakukan pekerjaan untuk mendapatkan upah biasanya disebut dengan pekerja atau pegawai. Berdasarkan garis besar penduduk, tenaga kerja dibedakan 2 macam yaitu tenaga kerja serta bukan tenaga kerja (Ari Welianto, 2020).

Selanjutnya pengertian tenaga kerja yang dikemukakan oleh Hamzah yaitu tenaga kerja adalah seseorang yang bekerja dengan hubungan kerja maupun tidak, dengan alat produksi utamanya bisa menggunakan fisik atau pikiran (Fahrizal, 2017).

\subsection{Kurs}

Kurs didefinisikan sebagai nilai tukar suatu mata uang terhadap mata uang lainya. Suatu kegiatan investasi dilaksanakan oleh investor jika nilai balik modalnya lebih tinggi dari penanaman modal. Adanya kurs berpengaruh terhadap estimasi investor untuk melakukan investasi dengan pertimbangan bahwa kurs akan member pengembalian modal yang lebih tinggi dibandingkan saat penanaman modal (Wardhani \& Suharyono, 2017).

Berdasarkan penelitian Sarah \& Sulasmiyati (2018) terkait pengaruh kurs serta inflasi terhadap FDI , menunjukkan bahwa variabel kurs dan variabel inflasi berpengaruh terhadap realisasi FDI dengan tingkat signifikansi $5 \%$. Besaran koefisien determinasi atau R2 senilai $64 \%$, sisanya senilai $36 \%$ dipengaruhi variabel-variabel lainya.

\section{METODE PENELITIAN}

\subsection{Sumber Data}

Pada studi ini, jenis penelitiannya menggunakan penelitian sekunder, menggunakan sumber data deret waktu dari tahun 1989 hingga 2019 pada data BPS dan beberapa instansi lainya. Variabel dependen adalah FDI dan variabel bebas yang digunakan PDB, Kurs, Ekspor dan Tenaga Kerja di Indonesia.

\subsection{Teknik Analisis Data}

Teknik analisis data dalam studi ini menggunakan regresi linear, dengan koreksi ECM atau error correction model, yang bertujuan mengetahui besaran pengaruh variabel independen terhadap variabel dependennya. Selanjutnya pengolahan data menggunakan aplikasi eviews 10.

1) Uji ECM

Pengujian ECM dimaksudkan sebagai langkah mengoreksi ketidakseimbangan pada investasi jangka pendek dan jangka panjang. Sebagai validitas data dalam pengujian ECM, berdasarkan nilai Error Correction Term, jika signifikan maka pengujian ECM dapat dibenarkan. Model dasar sistematis dalam uji ini yaitu :

$$
\mathrm{Y}=\mathrm{F}\left(\mathrm{GDP}_{\mathrm{t}}, \text { Ekspor }_{\mathrm{t}}, \mathrm{TK}_{\mathrm{t}}, \mathrm{Kurs}_{\mathrm{t}}\right)
$$

Oleh karena itu, persamaan model jangka panjang adalah :

$$
\mathrm{Y}_{\mathrm{t}}=\beta_{0}+\beta_{1} \mathrm{GDP}_{\mathrm{t}}+\beta_{2} \text { Ekspor }_{\mathrm{t}}+\beta_{3} \mathrm{Tk}_{\mathrm{t}}+\beta_{3} \text { Kurs }_{\mathrm{t}}+\varepsilon_{\mathrm{t}}
$$


Keterangan :

$\mathrm{GDP}_{\mathrm{t}}=$ Produk domestik Bruto per tahun periode 1986-2019

$\mathrm{TK}_{\mathrm{t}} \quad=$ Jumlah Tenaga kerja pertahun periode 1986-2019

Ekspor $_{\mathrm{t}}=$ Ekspor barang dan jasa pertahun periode 1986-2019

Kurs $_{\mathrm{t}}=$ Nilai tukar rupiah terhadap US\$ per tahun periode 1986-2019

$\varepsilon_{\mathrm{t}} \quad=$ Error Term

$\mathrm{Y} \quad=$ Investasi Asing Langsung (FDI) per tahun periode 1986-2019

Persamaan jangka pendek :

$D\left(Y_{t}\right)=\beta_{0}+\beta_{1} D\left(G P_{t}\right)+\beta_{2} D\left(\right.$ Ekspor $\left._{t}\right)+\beta_{3} D\left(T_{t}\right)+\beta_{3} D\left(\right.$ Kurs $\left._{t}\right)+\beta_{5}$ ECT $+\varepsilon_{t}$

Keterangan :

$\mathrm{D}\left(\mathrm{GDP}_{\mathrm{t}}\right)=$ Produk Domestik Bruto (PDB) dari tahun 1986-2019 yang dideferensiasi pada First Difference

$\mathrm{D}\left(\right.$ Ekspor $\left._{\mathrm{t}}\right)=$ Ekspor Barang dan Jasa dari tahun 1986-2019 yang dideferensiasi pada First Difference

$\mathrm{D}\left(\mathrm{TK}_{\mathrm{t}}\right)=$ Jumlah Tenaga Kerja dari tahun 1986-2019 yang dideferensiasi pada First Difference

$\mathrm{D}\left(\right.$ Kurs $\left._{\mathrm{t}}\right) \quad=$ Nilai tukar mata uang US\$ dari tahun 1986-2019 yang didiferensiasi pada First Difference

$\mathrm{D}\left(\mathrm{Y}_{\mathrm{t}}\right) \quad=$ Investasi Asing Langsung dari tahun 1986-2019 yang didiferensiasi pada First Difference

ECT $=$ Eror Correction Term

$\varepsilon_{\mathrm{t}} \quad=$ Erorr Term

2) Uji Asumsi Klasik

- Pengujian normalitas data

Pengujian ini bertujuan untuk memastikan sebaran data adalah normal sehingga dapat dilakukan uji selanjutnya.

- Uji Multikolenieritas

Pengujian ini dilakukan dengan tujuan mengetahui tingkat korelasi antar variabel bebas apakah meiliki korelasi yang tinggi atau tidak.

- Uji Heteroskedasititas

Pengujian ini bertujuan mencari adanya masalah heteroskedasititas atau tidak. Pengujian ini memerlukan uji Breusch. Nilai standar R2 dalam penelitian ini sebesar $5 \%$, Sehingga jika nilainya dibawah 5\% dapat dikatakan tidak ada permasalahan heteroskedasititas.

- Uji Autokorelasi

Bertujuan untuk mengetahui tingkat korelasi residual antar variabel pada model regresi. Dalam uji ini dibantu dengan Uji Durbin Watson. (F, 1967)

3) Uji Statistik

Pengujian statistik dilakukan guna mengetahui pengaruh variabel bebas terhadap variabel dependennya, dengan menguji beberapa uji statistik berikut: 
- $\quad$ Uji R $R^{2}$

Nilai $\mathrm{R}^{2} /$ koefisien determinasi, merupakan besarnya pengaruh variabel dependenya.

- Ujit

Uji t dilakukan untuk mengetahui besaran pengaruh variabel-variabel bebas terhadap variabel dependennya dengan parsial (setiap variabel).

- $\quad$ Uji F

Uji F dilakukan dengan tujuan mengetahui besarnya pengaruh variabel- variabel bebas terhadap variabel dependennya secara stimultan.

\section{HASIL DAN PEMBAHASAN}

Penilitian ini dilakukan dengan teknik analisis data regresi dan koreksi ECM (Error Correction Model) dengan tujuan mengetahui pengaruh jangka panjang dan pendek investasi asing langsung kepada Ekspor, PDB, TK, serta Kurs. Berikut ini merupakan tahapan pengujian dalam penelitian ini :

\subsection{Uji Stasioneritas}

Pengujian ini adalah syarat utama penggunaan metode ECM dengan menguji akar akar unit dengan maksud mengetahui integrasi data. Jika nilai t statistik lebih besar dari critical value maka bisa dibilang data adalah stasioner. Hasil uji stasioner dapat dilihat ditabel berikut,

Tabel 2 Hasil Uji Stasioner

\begin{tabular}{llllll}
\hline Variabel & ADF & \multicolumn{3}{c}{ Nilai Kritis Mutlak Mc Kinnon } & Ket. \\
& & $\mathbf{1 \%}$ & $\mathbf{5 \%}$ & $\mathbf{1 0 \%}$ & \\
\hline FDI & -1.120480 & -3.646342 & -2.954021 & -2.615817 & tidak stasioner \\
GDP & 1.362621 & -3.646342 & -2.954021 & -2.615817 & tidak stasioner \\
Export & -0.477643 & -3.646342 & -2.954021 & -2.615817 & tidak stasioner \\
TK & 0.616034 & -3.661661 & -2.960411 & -2.619160 & tidak stasioner \\
Kurs & -0.841188 & -3.646342 & -2.954021 & -2.615817 & tidak stasioner \\
\hline
\end{tabular}

Sumber : Eviews 10 (data diolah)

Berdasarkan pada tabel 2, bisa dilihat jika uji akar dalam penelitian ini menggunakan uji Augment Dicky Fuler. Perbandingan tingkat absolut antara nilai hitung dan nilai tabel dengan nilai kritis Mutlak Mc Kinnon. Perhitungan menunjukkan jika variabel GDP, FDi, Ekspor, TK dan Kurs pada tingkat kepercayaan sebesar 1\%, 5\%, dan 10\% adalah tidak stasioner, sehingga selanjutnya dilakukan uji integrasi pada tingkat First Difference agar dapat melihat data sudah stasioner atau tidak.

Tabel 3 Hasil Uji Akar Unit Tingkat First Difference

\begin{tabular}{llllll}
\hline Variabel & ADF & \multicolumn{3}{c}{ Nilai Kritis Mutlak Mc Kinnon } & Ket. \\
\hline & & $\mathbf{1 \%}$ & $\mathbf{5 \%}$ & $\mathbf{1 0 \%}$ & stasioner \\
FDI & -6.983083 & -3.653730 & -2.957110 & -2.617434 & stasioner \\
GDP & -3.726234 & -3.653730 & -2.957110 & -2.617434 & stasioner \\
Export & -4.763480 & -3.653730 & -2.957110 & -2.617434 & stasioner \\
TK & -6.017457 & -3.679322 & -2.967767 & -2.622989 & stasioner \\
\hline
\end{tabular}




\begin{tabular}{cccccc}
\hline Kurs & -6.789540 & -3.653730 & -2.957110 & -2.617434 & stasioner \\
\hline Sumber : Eviews 10 (data diolah) & & &
\end{tabular}

Dapat kita lihat hasil uji pada tingkat first difference di atas didapatkan analisis bahwa variabel-variabel sudah lolos dan dapat dikatakan stasioner.

\subsection{Uji Kointegrasi}

Dalam pengujian ini dilakukan untuk mengetahui residual dari persamaan regresi dalam penelitian. Hasil perhitungan didapatkan perkiraan jangka panjang untuk model persamaanya.Pengujian dilakukan menggunakan Eviews 10 dengan hasil sebagai berikut:

Tabel 4 Hasil Uji Nilai Residual (ECT)

\begin{tabular}{llllll}
\hline Variable & \multirow{2}{*}{ ADF } & \multicolumn{2}{c}{ Nilai Kritis Mutlak Mc Kinnon } & Keterangan \\
& & $\mathbf{1 \%}$ & $\mathbf{5 \%}$ & $\mathbf{1 0 \%}$ & \\
\hline ECT & -3.810460 & -3.886751 & -3.052169 & -2.666593 & Stasioner \\
\hline
\end{tabular}

Sumber : Eviews 10 (data diolah)

Dari uji tersebut menunjukkan probabilitas ECT $<0.05$. Selanjutnya terkait nilai tStatistik ECT bernilai negatif yaitu sebesar -3.810460. Dalam jangka panjang berdasarkan data hasilnya saling berkesinambungan, sehingga dapat dilakukan pengujian kointegrasi dan uji ECM. Hasil dari Uji Koitegrasi adalah sebagai berikut :

Tabel 5 Hasil Uji Kointegrasi

Unrestricted Cointegration Rank Test (Trace)

\begin{tabular}{lllll}
\hline \hline $\begin{array}{l}\text { Hypothesized } \\
\text { No. of CE(s) }\end{array}$ & Eigenvalue & $\begin{array}{l}\text { Trace } \\
\text { Statistic }\end{array}$ & $\begin{array}{l}\mathbf{0 . 0 5} \\
\text { Critical Value }\end{array}$ & Prob.** \\
\hline \hline None * & 0.969493 & 199.4026 & 79.34145 & 0.0000 \\
At most $1 *$ & 0.862514 & 112.1578 & 55.24578 & 0.0000 \\
At most 2 & 0.767428 & 62.55201 & 35.01090 & 0.0000 \\
At most 3 & 0.500929 & 26.08812 & 18.39771 & 0.0035 \\
At most 4 & 0.294267 & 8.712942 & 3.841466 & 0.0032 \\
\hline \hline
\end{tabular}

Tracetest indicates 5 cointegrating eqn(s) at.the 0.05 level.

* denotes.rejection of the hypothesis at the 0.05 level

**MacKinnon-Haug-Michelis (1999) p-values

Unrestricted Cointegration Rank Test (Maximum Eigen value)

\begin{tabular}{lllll}
\hline \hline $\begin{array}{l}\text { Hypothesized } \\
\text { No. of CE(s) }\end{array}$ & Eigenvalue & $\begin{array}{l}\text { Max-Eigen } \\
\text { Statistic }\end{array}$ & $\begin{array}{l}\mathbf{0 . 0 5} \\
\text { Critical Value }\end{array}$ & Prob.** \\
\hline \hline None $*$ & 0.969493 & 87.24485 & 37.16359 & 0.0000 \\
At most $1 *$ & 0.862514 & 49.60574 & 30.81507 & 0.0001 \\
At most $2 *$ & 0.767428 & 36.46389 & 24.25202 & 0.0008
\end{tabular}




\begin{tabular}{lllll} 
At most $3 *$ & 0.500929 & 17.37517 & 17.14769 & 0.0463 \\
At most $4 *$ & 0.294267 & 8.712942 & 3.841466 & 0.0032 \\
\hline
\end{tabular}

Max-eigenvalue test indicates 5 cointegrating eqn(s) at the 0.05 level

$*$ denotes rejection of the hypothesis.at the 0.05 level

**MacKinnon-Haug-Michelis (1999 p-values

Sumber: Eviews 10 (data diolah)

Dari tabel 5, didapatkan angka trace statistik 199.4026> nilai kritis 5\% yaitu 79.34145. Nilai Maximum Eigen value Statistik sebesar $87.24485>$ dari nilai kritis 5\% sebesar 37.16359. Berdasarkan pengujian ini dapat ditarik kesimpulan yaitu terdapat kointegrasi ke empat variabel yaitu GDP, FDI, Ekspor, TK dan Kurs. Hasil ini berarti bahwa kesetimbangan antar variabel adalah jangka panjang.

\subsection{Uji ECM}

Setelah beberapa pengujian yang dilakukan maka diperoleh hasil dari estimasi uji ECM.Disajikan dalam tabel berikut :

Tabel 6 Hasil Estimasi ECM Jangka Panjang

\begin{tabular}{lllll}
\hline \hline Variable & Coefficient & Std. Error & t-Statistic & Prob. \\
\hline \hline GDP & 0.014881 & 0.007349 & 2.024978 & 0.0525 \\
EXPORT & 0.085010 & 0.039444 & 2.155194 & 0.0399 \\
TK & -45.91894 & 119.7738 & -0.383381 & 0.7043 \\
KURS & -571273.5 & 493159.6 & -1.158395 & 0.2565 \\
C & $3.11 \mathrm{E}+09$ & $1.23 \mathrm{E}+10$ & 0.252665 & 0.8024 \\
\hline \hline R-squared & 0.882416 & Mean dependen var & $7.32 \mathrm{E}+09$ \\
Adjusted R-squared & 0.865618 & S.D. dependen var & $9.17 \mathrm{E}+09$ \\
S.E. of regression & $3.36 \mathrm{E}+09$ & Akake info criterion & 46.84788 \\
Sum squared resid & $3.16 \mathrm{E}+20$ & Schwaz criterion & 47.07462 \\
Log likeihood & -767.9900 & Hannan-Quin criter & 46.92417 \\
F-statistic & 52.53167 & Durbin-Watson stats & 2.022183 \\
Prob. (F-statstic) & 0.000000 & & \\
\hline \hline
\end{tabular}

Sumber : Eviews 10 (data diolah)

Berdasarkan tabel diketahui jika nilai prob (F-statistic) yaitu 0.00000 yang berarti $<$ nilai $\alpha=5 \%$, sehingga diartikan signifikan. Berdasarkan ini, tersebut menunjukkan jika variabel GDP, Ekspor, Tk dan kurs secara simultan berpengaruh terhadap variabel FDI.

Selanjutnya regresi jangka panjang berdasarkan nilai (R2) X $100 \%$ adalah $0.882416 \mathrm{X}$ $100 \%=88,24 \%$ dijelaskan oleh variabel GDP, Ekspor, TK, Kurs dan sisanya sebesar $11,76 \%$ diterangkan oleh variabel diluar penelitian.

Tabel 7 Hasil Estimasi ECM Jangka Pendek

\begin{tabular}{lllll}
\hline \hline Variable & Coefficient & Std. Error & t-Statistic & Prob. \\
\hline \hline
\end{tabular}




\begin{tabular}{lllll} 
D1_GDP & -0.006143 & 0.020516 & -0.299417 & 0.7671 \\
D1_EXPORT & 0.088668 & 0.051395 & 1.725203 & 0.0968 \\
D1_TK & 633.2149 & 453.6795 & 1.395732 & 0.1751 \\
D1_KURS & -550235.0 & 569923.7 & -0.965454 & 0.3436 \\
RESID01_ETC2(-1) & -1.157746 & 0.200608 & -5.771172 & 0.0000 \\
C & $-1.49 \mathrm{E}+09$ & $1.69 \mathrm{E}+09$ & -0.885606 & 0.3843 \\
\hline \hline R-squared & 0.705284 & Mean dependen var & $6.66 \mathrm{E}+08$ \\
Adjusted R-squared & 0.646341 & S.D. dependen var & $5.24 \mathrm{E}+09$ \\
S.E. of regression & $3.12 \mathrm{E}+09$ & Akaike info criter. & 46.73049 \\
Sum squared res. & $2.43 \mathrm{E}+20$ & Schwaz criter. & 47.00803 \\
Log.likelihood & -718.3226 & Hannan-Quinn criter & 46.82096 \\
F-statistic & 11.96548 & Durbin-Watson stats & 2.250751 \\
Prob (F-statistic) & 0.000006 & & \\
\hline \hline
\end{tabular}

Sumber : Eviews 10 (data diolah)

Berdasarkan tabel 7, didapatkan angka koefisien ECT adalah -1.157746. Hasil regresi ECT dari probabilitas ECT adalah 0.0000, diartikan variabel signifikan dengan taraf signifikansi $\alpha=1 \%$. Sehingga dapat disimpulkan jika model ECM cocok dalam studi kali ini. Sehingga uji ECM bisa dikatakan valid.

Selanjutnya, diketahui nilai prob. $\mathrm{F}$ yaitu 0.000006 . Berarti bahwa $\mathrm{F}<$ nilai $\alpha=$ $1 \%$, sehingga dapat dikatakan signifikan. Hal tersebut berarti GDP, Ekspor, TK, dan Kurs secara simultan berpengaruh terhadap variabel FDI.

Perhitungan regresi jangka pendek didapatkan dengan mrngalikan (R2) X 100\%, yaitu 0.705284 dikali $100 \%=70,52 \%$ (dijelaskan pada variabel GDP, Ekspor, TK, Kurs). Selanjutnya sisanya yaitu senilai $29,48 \%$ dijelaskan variabel lain.

\subsection{Uji Asumsi Klasik}

a) Uji Normalitas

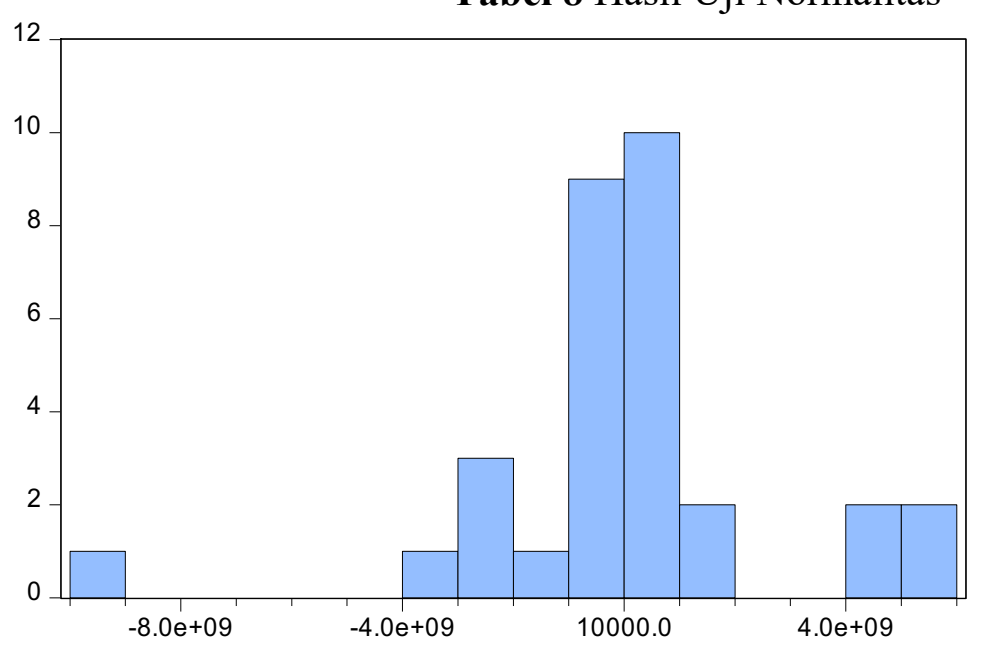

Series: Residuals Sample 19872019 Observations 31

Mean $\quad 1.23 \mathrm{e}-07$

Median $\quad 13276311$

Maximum $\quad 5.95 e+09$

Minimum $\quad-9.58 \mathrm{e}+09$

Std. Dev. $\quad 2.85 \mathrm{e}+09$

Skewness $\quad-0.658381$

Kurtosis $\quad 6.102620$

Jarque-Bera $\quad 14.67347$

Probability $\quad 0.000651$

Sumber: Eviews 10 (data diolah) 
Uji normalitas diatas menunjukan bahwa prob Jarque-Bera sebesar 14.67347, sehingga dengan prob. $0.000651<$ tingkat signifkansi 0,05 (5\%), yang mengartikan bahwa model ini tidak normal. Meskipun dari hasil uji Normalitasnya tidak lolos data ini tetap digunakan karena menggunakan asumsi klasik linear regresi model, dimana penggunaan data 34 sampel sudah merupakan sampel yang besar.

b) Uji Heterokedastisitas

Tabel 9 Hasil Uji Heteroskedastisitas

Heteroskedasticity Test: White

\begin{tabular}{llll}
\hline \hline F-statistic & 4.214050 & Prob. F(20,10) & 0.0118 \\
Obs*R-squared & 27.71196 & Prob. Chi-Square(20) & 0.1164 \\
Scaled explained SS & 45.98191 & Prob. Chi-Square(20) & 0.0008 \\
\hline \hline
\end{tabular}

Sumber : Eviews 10 (data diolah)

Dari Uji Breusch-Pagan-Godfrey diatas ,didapatkan nilai Chi-Square 0.1164 serta $0.0008<$ nilai signnifikansi 0,05 (5\%), Jadi kesimpulannya penelitian ini tidak terbebas dari heteroskedastisitas.

Akan tetapi data ini tetap digunakan , karena data nya merupakan data time series yang merupakan data real dan terjamin validitas datanya.

c) Uji Autokorelasi

Tabel 10 Hasil Uji Autokorelasi

Breusch-Godfrey Serial Correlation LM Test:

\begin{tabular}{llll} 
F-statistic & 2.413850 & Prob. F(2,23) & 0.1118 \\
Obs*R-squared & 5.378048 & Prob. Chi-Square(2) & 0.0679 \\
\hline \hline
\end{tabular}

Sumber : Eviews 10 (data diolah)

Dalam melakukan uji autokorelasi dalam studi ini memakai uji Breusch-Godfrey Correlation LM Test. Berdasarkan tabel diatas angka prob. Ci-Square pada LM Test adalah $0.1118>$ tingkat signifkansi $0,05(5 \%)$. Sehingga diartikan bahwa regresi antar residual tidak terdapat adanya autokorelasi. Uji autokorelasi yang wajib lolos dikarenakan peneliti menggunakan hasil dari F-statistic dan juga R-squared.

\subsection{Uji Statistik}

Tabel 11 Hasil Estimasi ECM Jangka Panjang

\begin{tabular}{|c|c|c|c|c|}
\hline Variable & Coefficient & Std. Error & t-Statistic & Prob. \\
\hline GDP & 0.014881 & 0.007349 & 2.024978 & 0.0525 \\
\hline EXPORT & 0.085010 & 0.039444 & 2.155194 & 0.0399 \\
\hline $\mathrm{TK}$ & -45.91894 & 119.7738 & -0.383381 & 0.7043 \\
\hline KURS & -571273.5 & 493159.6 & -1.158395 & 0.2565 \\
\hline
\end{tabular}




\begin{tabular}{lllll} 
C & $3.11 \mathrm{E}+09$ & $1.23 \mathrm{E}+10$ & 0.252665 & 0.8024 \\
\hline \hline R-squared & 0.882416 & Mean dependen var & $7.32 \mathrm{E}+09$ \\
Adjusted R-squared & 0.865618 & S.D. dependen var & $9.17 \mathrm{E}+09$ \\
S.E. of regression & $3.36 \mathrm{E}+09$ & Akaike info criter. & 46.84788 \\
Sum squared res & $3.16 \mathrm{E}+20$ & Schwarz criter. & 47.07462 \\
Log likeihood & -767.9900 & Hannan-Quinn criter. & 46.92417 \\
F-statistic & 52.53167 & Durbin-Watson stats & 2.022183 \\
Prob(F-statistic) & 0.000000 & & \\
\hline \hline
\end{tabular}

Sumber : Eviews 10 (data diolah)

Tabel 12 Hasil Estimasi ECM Jangka Pendek

\begin{tabular}{lllll}
\hline \hline Variable & \multicolumn{2}{l}{ Coefficient Std. Error } & t-Statistic & Prob. \\
\hline \hline D1_GDP & -0.006143 & 0.020516 & -0.299417 & 0.7671 \\
D1_EXPORT & 0.088668 & 0.051395 & 1.725203 & 0.0968 \\
D1_TK & 633.2149 & 453.6795 & 1.395732 & 0.1751 \\
D1_KURS & -550235.0 & 569923.7 & -0.965454 & 0.3436 \\
RESID01_ETC2(-1) & -1.157746 & 0.200608 & -5.771172 & 0.0000 \\
C & $-1.49 \mathrm{E}+09$ & $1.69 \mathrm{E}+09$ & -0.885606 & 0.3843 \\
\hline \hline R-squared & 0.705284 & Mean dependent var & $6.66 \mathrm{E}+08$ \\
Adjusted R-squared & 0.646341 & S.D. dependent var & $5.24 \mathrm{E}+09$ \\
S.E. of regression & $3.12 \mathrm{E}+09$ & Akaike info criter. & 46.73049 \\
Sum squared res. & $2.43 \mathrm{E}+20$ & Schwarz criter. & 47.00803 \\
Log likelihood & -718.3226 & Hannan-Quinn criter. & 46.82096 \\
F-statistic & 11.96548 & Durbin-Watson stat & 2.250751 \\
Prob(F-statistic) & 0.000006 & & & \\
\hline \hline
\end{tabular}

Sumber : Eviews 10 (data diolah)

1) Koefisien Determinasi R2

Estimasi regresi jangka panjang didapatkan dari nilai R2 dikali 100\%. Nilai R2 $0.882416 \times 100 \%=88,24 \%$ (dijelaskan pada variabel GDP, Ekspor, TK, Kurs) sedangkan sisanya $11,76 \%$ dijelaskan oleh variabel-variabel lainya. Selanjutnya hasil regresi jangka pendek didapatkan dari nilai R2 dikali 100\%. Nilai (R2) $0.705284 \times 100 \%=70,52 \%$ (dijelaskan pada variabel GDP, Ekspor, TK, Kurs) sedangkan sisanya 29,48 \% dijelaskan variabel-variabel lainya.

2) Uji t (Uji Signifikansi secara Parsial)

a) Gross Domestic Product (GDP)

Berdasarkan persamaan jangka panjang didapatkan nilai t statistiknya adalah 2.024978. Dengan $\mathrm{t}$ tabel $\alpha=5 \%$ dan $\mathrm{df}=28$ adalah 2.048 , sehingga $\mathrm{t}$ statistik $<\mathrm{t}$ tabel yaitu $2.024978<$ 2.028, dapat diartikan dalam jangka panjang GDP tidak signifikan \& berpengaruh positif terhadap variabel FDI, dan nilai probabilitasnya adalah 0.0000 yang berarti signifikan dalam $\operatorname{taraf} \alpha=1 \%$. Selanjutnya persamaan jangka pendek diperoleh nilai t hitung adalah 0.299417. Jadi nilai $\mathrm{t}$ statistik $<\mathrm{t}$ tabel yaitu $-0.299417<2.028$, diartikan bahwa dalam jangka pendek 
GDP tidak signifikan dan berpengaruh negatif terhadap variabel FDI, \& nilai probabilitas sebessar 0.000006 signifikan dalam taraf $\alpha=1 \%$ atau 0.01 .

b) Ekspor

Berdasarkan uji t variabel Ekspor didapatkan berdasarkan perhitungan persamaan jangka panjang didapatkan nilai t statistiknya adalah 2.155194. Nilai t tabel $\alpha=5 \%$ \& df $=28$ sebesar 2.048. Sehingga nilai $t$ statistik $>\mathrm{t}$ tabel yaitu sebesar $2.155194>2.028$, dapat diartikan bahwa dalam jangka panjang variabel Ekspor signifikan dan berpengaruh positif terhadap variabel FDI, dengan probabilitas sebesar 0.0000 signifikan dalam taraf $\alpha=1 \%$.

Selanjutnya dalam persamaan jangka pendek diperoleh nilai t hitung sebesar 1.725203 . Jadi nilai t-statistik $<\mathrm{t}$ tabel yaitu sebesar $1.725203<2.028$ yang dapat diartikan bahwa dalam jangka pendek variabel Ekspor tidak signifikan dan berpengaruh Positif kepada variabel FDI, dengan probabilitas sebesar 0.000006 signifikan dalam taraf $\alpha=1 \%$ atau 0.01 .

c) Tenaga Kerja (Labor)

Berdasarkan uji t variabel Tenaga Kerja (Labor) didapatkan hasil dari persamaan jangka panjang dengan nilai t statistiknya sebesar -0.383381 dan nilai t tabel $\alpha=5 \%$ serta $\mathrm{df}=28$ sebesar 2.048. Sehingga nilai t statistic $<$ t tabel yaitu $-0.383381<2.028$. Berarti bahwa jangka panjang variabel Labor tidak signifikan dan berpengaruh Negatif terhadap variabel FDI, dengan probabilitas sebesar 0.0000 signifikan dalam taraf $\alpha=1 \%$.

Selanjutnya persamaan jangka pendek diperoleh nilai t hitung sebesar 1.395732. Jadi niali t-statistik $<\mathrm{t}$ tabel yaitu senilai $1.395732<2.028$, dapat diartikan bahwa dalam jangka pendek variabel Ekspor tidak signifikan dan berpengaruh Positif terhadap variabel FDI, sedangkan nilai probabilitasnya adalah 0.000006 signifikan dalam taraf $\alpha=1 \%$ atau 0.01 .

d) Kurs

Berdasarkan uji $\mathrm{t}$ variabel Kurs didapatkan bahwa persamaan jangka panjang didapatkan nilai t statistiknya sebesar -1.158395 . Selanjutnya nilai t tabel $\alpha=5 \% \& \mathrm{df}=28$ dengan nilai 2.048. Jadi nilai t statistik $<$ t tabel yaitu $-1.158395<2.028$, diartikan bahwa dalam jangka panjang variabel Kurs tidak signifikan dan berpengaruh Negatif terhadap variabel FDI, dengan probabilitas senilai 0.0000 signifikan dalam taraf $\alpha=1 \%$.

Selanjutnya persamaan jangka pendek diperoleh t hitung sebesar -0.965454 . Jadi nilai $t$ statistik $<$ t tabel yaitu $-0.965454<2.028$ diartikan bahwa dalam jangka pendek variabel Kurs tidak signifikan dan berpengaruh negatif terhadap variabel FDI, dengan probabilitas senilai 0.000006 signifikan dalam taraf $\alpha=1 \%$ atau 0.01 .

3) Uji F

Berdasarkan pada estimasi ECM pada jangka pendek diperoleh nilai F hitung 11.96548, $\mathrm{F}$ hitung $>\mathrm{F}$ tabel yaitu $11.96548>2.714$, probabilitas sebesar 0.000006 yang signifikan terhadap $\alpha=1 \%$ atau 0.01. diartikan bahwa variabel GDP, Ekspor, Tk dan kurs berpengaruh pada variabel Foreign direct Invesment (FDI).

Berdasarkan estimasi ECM pada jangka panjang nilainya sebesar 52.53167. nilai $\mathrm{F}$ hitung $>\mathrm{F}$ tabel yaitu $52.53167>2.714$, probabilitasnya sebesar 0.000000 yang signifikan terhadap $\alpha=1 \%$ atau 0.01 . berarti bahwa variabel GDP, Ekspor, Tk dan kurs berpengaruh pada variabel FDI. 


\section{KESIMPULAN}

1. Dalam jangka panjang Produk Domestik Bruto mempunyai koefisien positif, akan tetapi tidak signifikan terhadap FDI. Selanjutnya dalam jangka pendek, PDB nilai koefisiennya negatif dan berpengaruh secara signifikan terhadap FDI.

2. Ekspor bernilai positif dan tidak berpengaruh signifikan terhadap FDI dalam jangka panjang. Sedangkan jangka pendeknya hubungannya positif dan tidak signifikan terhadap FDI.

3. Labor dalam jangka panjang memiliki koefisien negatif serta tidak berpengaruh signifikan terhadap penanaman modal asing langsung. Selanjutnya dalam jangka pendek hubungannya positif serta tidak berpengaruh signifikan terhadap FDI.

4. Kurs bernilai negatif serta tidak berpengaruh secara signifikan terhadap FDI, selanjutnya dalam jangka pendek bernilai positif dan signifikan terhadap FDI.

Selain itu, kelemahan pada penelitian ini yaitu terkait hasil uji asumsi klasik hanya uji autokoleritas saja yang lolos.

\section{DAFTAR PUSTAKA}

Ari Welianto. (2020). Ketenagakerjaan: Pengertian, kelompok dan Klasifikasi tenaga kerja. Kompas.Com.

https://www.kompas.com/skola/read/2020/07/14/130000269/ketenagakerjaanpengertian-kelompok-dan-klasifikasi-tenaga-kerja?page $=$ all

Benny, J. (2013). Ekspor dan impor pengaruhnya terhadap posisi cadangan devisa di Indonesia. Jurnal EMBA: Jurnal Riset Ekonomi, Manajemen, Bisnis Dan Akuntansi, 1(4).

Eliza, M. (2013). Analisis Pengaruh Variabel Makroekonomi Terhadap Investasi Asing. Jurnal Ilmiah Mahasiswa FEB, 19.

F, K. Ge. (1967). 済無No Title No Title No Title. Angewandte Chemie International Edition, 6(11), 951-952., 40-49.

Fahrizal, Y. (2017). BAB II TINJAUAN TEORI A. Tenaga Kerja. Journal of Chemical Information and Modeling, 53(9), 8-15.

Febriana, A., \& Muqorobbin, M. (2002). Investasi Asing Langsung Di Indonesia Dan Faktor Yang Mempengaruhinya. Jurnal Akuntansi Dan Keuangan, 4(1), 17-35. https://doi.org/10.9744/jak.4.1.pp.17-35

Hatemi-J, A., \& Irandoust, M. (2005). Foreign aid and economic growth: New evidence from panel cointegration. Journal of Economic Development, 30, 71-80.

Jhingan, M. L. (1988). Ekonomi pembangunan dan perencanaan, ed. Ke-16. Rajawali Press, Jakarta.

KEMENPERIN. (2003). Undang - Undang RI No 13 tahun 2003. Ketenagakerjaan, 1.

Latumaerissa, J. R. (2015). Perekonomian Indonesia dan dinamika ekonomi global. Mitra Wacana Media.

Lembong, J. D. (2013). Analisis Pengaruh Pdb, Inflasi, Suku Bunga, Dan Krisis Moneter Terhadap Fdi Di Indonesia Tahun 1981-2012. Diponegoro Journal of Economics, 2(4). 
Sarah, \& Sulasmiyati. (2018). Pengaruh inflasi, ekspor dan tenaga kerja terhadap Produk Domestik Bruto ( Malaysia, Singapura, dan Thailand). Jurnal Administrasi Bisnis $(J A B), 63(1), 8-16$.

Sarwedi, S. (2002). Investasi Asing Langsung Di Indonesia Dan Faktor Yang Mempengaruhinya. Jurnal Akuntansi Dan Keuangan, 4(1), 17-35.

Sukirno, S. (2011). Ekonomi Makro teori pengantar, edisi ketiga. Jakarta: PT Raja Grafindo Persada.

Sumarni, A. S., \& Rahmawati, R. (2007). Relevansi Nilai Informasi Arus Kas dengan Rasio Laba Harga dan Perubahan Laba Harga Sebagai Variabel Moderasi: Hubungan Nonlinier. Jurnal Akuntansi Dan Auditing Indonesia, 11(1).

Wardhani, D. P., \& Suharyono. (2017). Pengaruh Nilai Total Ekspor Dan Variabel Makroekonomi Lainnya terhadap Foreign Direct Investment ( FDI ) di Indonesia. Jurnal Administrasi, 50(5), 171-180.

Zsaszya. (2019). Apa itu Foreign Direct Investment? https://www.onlinepajak.com/tentang-pph-final/foreign-direct-investment 